Research Article

\title{
Fracture Characteristics and Zoning Model of Overburden during Longwall Mining
}

\author{
Zhengyi Ti $\left(\mathbb{D},{ }^{1}\right.$ Jiazhen Li $\left(\mathbb{D},{ }^{1}\right.$ Meng Wang $\left(\mathbb{D},{ }^{1}\right.$ Xiaoyan Li, ${ }^{2,3}$ Zhupeng Jin ${ }^{\circ},{ }^{4}$ \\ Caiwang Tai $\mathbb{D}^{1},{ }^{1}$ and Kang Wang $\mathbb{D}^{1}$ \\ ${ }^{1}$ College of Mining Engineering, Liaoning Technical University, Fuxin 123000, China \\ ${ }^{2}$ Engineering Laboratory of Deep Mine Rockburst Disaster Assessment, Jinan 250104, China \\ ${ }^{3}$ Exploration Research Institute of Shandong Coal Field Geology Bureau, Jinan 250104, China \\ ${ }^{4}$ School of Mining Engineering, Heilongjiang University of Science and Technology, Harbin 150027, China
}

Correspondence should be addressed to Jiazhen Li; 1.jz2000@163.com

Received 23 June 2021; Revised 5 August 2021; Accepted 19 August 2021; Published 2 September 2021

Academic Editor: Chao Xu

Copyright (C) 2021 Zhengyi Ti et al. This is an open access article distributed under the Creative Commons Attribution License, which permits unrestricted use, distribution, and reproduction in any medium, provided the original work is properly cited.

The fracture characteristics and zoning model of overburden during longwall mining are the basis of coal mine disaster prevention. However, the existing theoretical model is inconsistent with the field measurement. In order to further research into the strata's fracture characteristics and optimize the overburden's zoning model, we used the elasticity and Winkler foundation theory to establish first fracture and periodic fracture mechanics models of clamped boundary supported by an elastic foundation with a key stratum as the research object. We analyzed the stress distribution characteristics and fracture evolution pattern of the mining-induced key stratum. We analyzed the zoning characteristics of mining-induced overburden and established the zoning model according to different fracture mechanisms. The results show that the key stratum formed a double "O-X" shaped interconnected fracture zone after the first fracture. The key stratum formed a double "C-K" shaped interconnected fracture zone after the periodic fracture. We divided the mining-induced overburden into three zones along the horizontal direction: the original rock zone, the inverted triangular compression-shear fracture zone, and the trapezoidal tensile fracture zone. The study revealed the mechanism of inverted step fracture in the separation zone, explained the fracture mechanism of the coal pillar support zone, and has significant theoretical value for the prevention and control of water disasters, gas outbursts, and strata movement.

\section{Introduction}

The deformation and fracture process of mining-induced overburden is the main reason for coal mine production accidents [1-4]. Therefore, it is necessary to conduct indepth research on the fracture characteristics and zoning model of mining-induced overburden. Currently, strata mechanical models are widely using the plate theory and beam theory. Zuo et al. simplified the roof strata into the fixed beam and cantilever beam with uniform load. The principal tensile stress contour revealed the first oblique tensile fracture mechanism on both sides of the fixed beam's lower edge and the periodic oblique tensile fracture mechanism of the upper edge of the cantilever beam's fixed end [5]. He et al. established the mechanical model of elastic foundation beam, calculated the ultimate fracture distance of the main roof, and revealed the fracture characteristics of the advanced coal wall of the main roof [6]. Qian et al. regarded the main roof as a fixed elastic thin plate and revealed the "O-X" fracture characteristics according to the bending moment distribution of the main roof [7]. Based on plastic mechanics, Jiang et al. judged that the plastic yield line of roof strata presented "O-X" structure characteristics according to energy dissipation [8]. Elastic foundation beam theory can only analyze the fracture characteristics of the roof section. It cannot analyze the roof's overall structure. The mechanical models of a thin elastic plate with fixed and simple support 
ignore the influence of elastic support of coal seam (rock strata) on the roof [9].

The vertical coal seam direction is widely recognized in the three-zone theory based on the continuity of mining-induced overburden, as shown in Figure 1. In parallel coal seam direction, the three-zone theory divided according to the carrying characteristics of overburden is shown in Figure 2. Zuo et al. established an analogous hyperbola subsidence model (AHSM) according to the fracture boundary of overburden in the three-zone theory. It is considered that the strata movement boundary is two inner concave curves, which are symmetrical along the center of goaf [10-12]. Xu et al. established a trapezoidal caving model of strata movement induced by coal mining according to the inverted step fracture form of overburden in the three-zone theory [13]. Guo et al. established a new method of predicting the fractured water-ducting zone (FWCZ) height due to longwall coal mining according to the trapezoidal fracture zone in the three-zone theory [14].

However, the above-mentioned overburden's zoning model is inconsistent with the measured results. The measured results show that the fracture area of mininginduced overburden is larger than the exploitation area [16-18]. Chen et al. carried out microseismic monitoring on the coal mining panel. The microseismic activity caused by longwall mining was mainly distributed in the coal pillar support zone and separation zone. The peak value of the microseismic events near the panel is located in front of the coal wall, consistent with the peak value of the front abutment pressure. In the depth direction, the microseismic activity is mainly distributed in the lower part of the continuous deformation zone [19]. Yu et al. arranged detection boreholes in front of the longwall panel. The digital panoramic imaging (DPI) technique was used to observe the internal fracture at different relative positions between the borehole and the longwall panel, which confirmed an advanced fracture in the roof strata [20]. Shi et al. carried out microseism and stress monitoring in deep mining. The strata movement range in deep mining was expanded. The influence distance in front of the longwall panel was far more than the influence distance in shallow mining [21]. Palchik measured the amount of natural gas emission in overburden during longwall coal excavation by drilling. He studied the distribution of mining-induced fractures based on the change in natural gas emissions. When the longwall panel did not exceed the drilling, the roof produced interconnected fractures, resulting in the emission of natural gas [22]. Hosseini et al. used the double-difference passive seismic velocity tomography to evaluate stress changes around the longwall mining panel. They found that the increase of front abutment pressure and side abutment pressure led to the expansion of fracture [23]. Cheng et al. used the microseismic monitoring technique to investigate the distribution law of strata movement released by coal mining. It was revealed that shear fracture mainly occurs in pillar support zone and tensile fracture mainly occurs in separation zone [24].
The deformation and fracture process of mining-induced overburden is the main factor of surface subsidence, roadway instability, mine water, coal and gas outburst (CGO), and rockburst [2-4]. Therefore, it is necessary to clarify the mechanism of overburden fracture and the fracture characteristics of different regions and provide a theoretical basis for the prevention and control of mine disasters. We established the overall mechanical model of mining-induced strata supported by the elastic foundation with the Winkler foundation. We analyzed the characteristics and dynamic evolution law of stress field and fracture field of mining-induced strata. According to the different fracture mechanisms of roof strata in different zones, we analyzed the zoning characteristics of mining-induced overburden and established a mining-induced overburden zoning model.

\section{Key Strata Mechanical Model}

2.1. Mechanical Model of KS First Fracture. The physical and mechanical parameters of sedimentary rock are not uniform in the vertical direction. If there are hard and thick strata in the overburden, they control the deformation and fracture of the overburden, which are called the key strata [25]. The key strata (KS) theory has been widely accepted and used in academia and industry $[26,27]$. The key strata move synchronously with the strata they control. According to the control range of the key strata, they can be divided into the primary key stratum (PKS) and the inferior key stratum (IKS) [25]. According to the key strata theory, the strata movement is grouped from bottom to top. The boundary between two zones is usually the key stratum [28]. Studying the fracture characteristics of the key strata can clarify the fracture characteristics of the overburden [29]. If the overburden is weak strata, there are no key strata, which is not in the scope of this article.

The immediate roof fractures first due to the lower strength during longwall mining. The KS is in a state of suspension due to the loss of support. The boundary condition of KS is elastic clamped because the KS is tied by relatively weak rock strata $[9,25,30]$. The KS fracture's size generally meets the basic assumption of elasticity [31]. The first fracture thin plate mechanical model of KS is shown in Figure 3. The $x$-axis is the direction of the longwall panel, and the $y$-axis is the direction of excavation. The $A_{1} B_{1} C_{1} D_{1}$ area is in a suspended state called an unsupported zone below the goaf. The $A B C D$ area is clamped by the relatively weak rock strata called the elastic foundation-supported zone [9]. There is a fixed boundary far from the elastic foundation-supported zone. The section figure of the KS structure indicates its stress state. The load of the unsupported zone is $q_{1}$, which is the sum of self-weight and controlled weak rock strata load. The elastic foundation-supported zone load is $q_{2}$, which is the sum of the transfer load of the unsupported zone and the field stress [30].

The basic differential equations of unsupported zone and elastic foundation-supported zone are as follows [31]: 


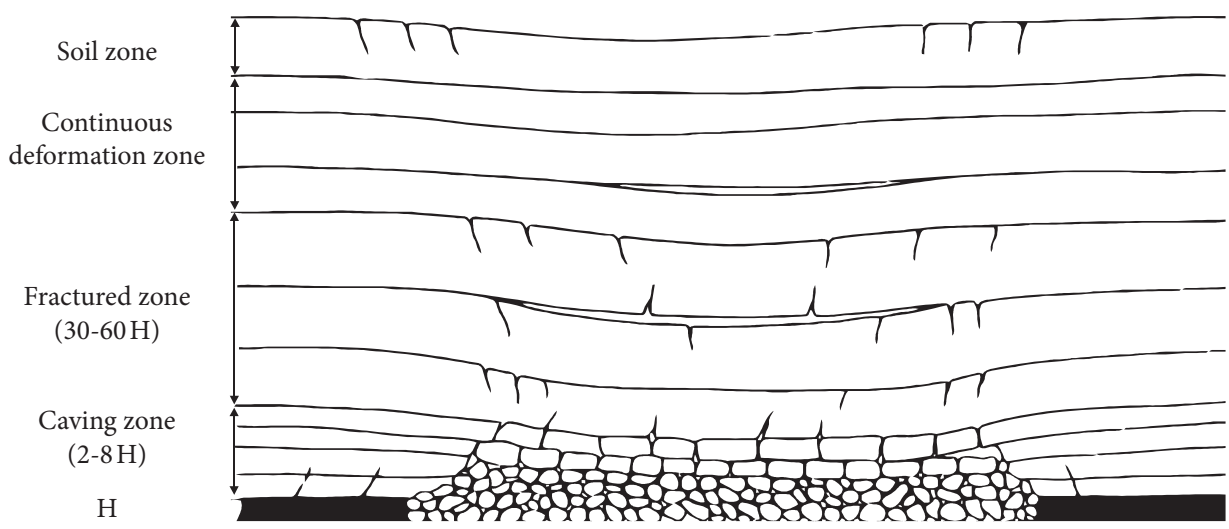

Figure 1: Vertical three-zone distribution of overburden above goaf [1]: $H$ is the thickness of coal seam.

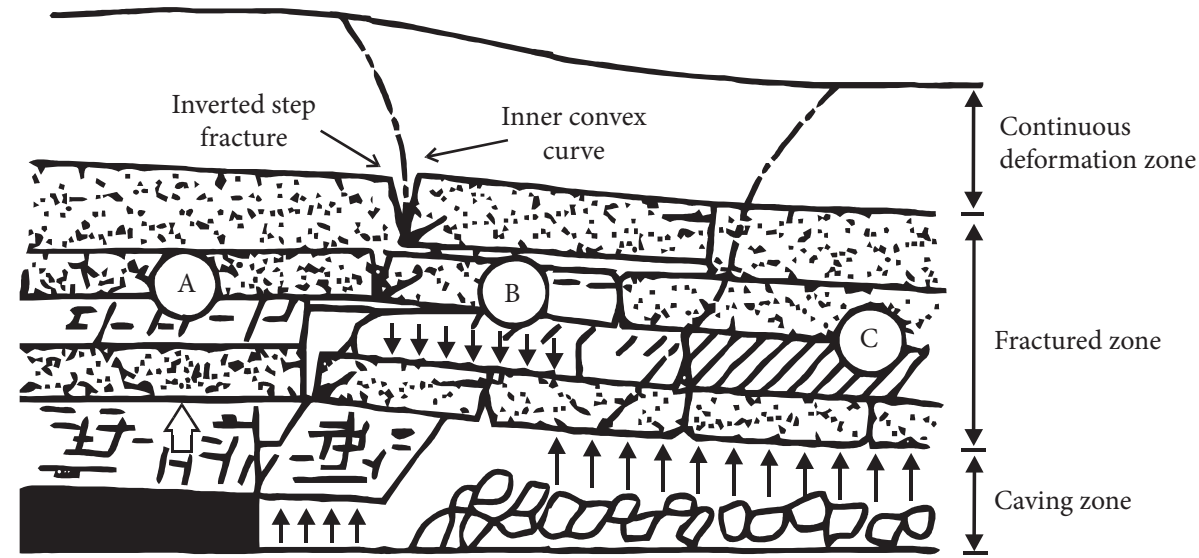

FIGURE 2: Horizontal three-zone distribution of overburden above goaf [15]: A is the coal pillar supporting zone; B is the separation zone; C is the recompaction zone.

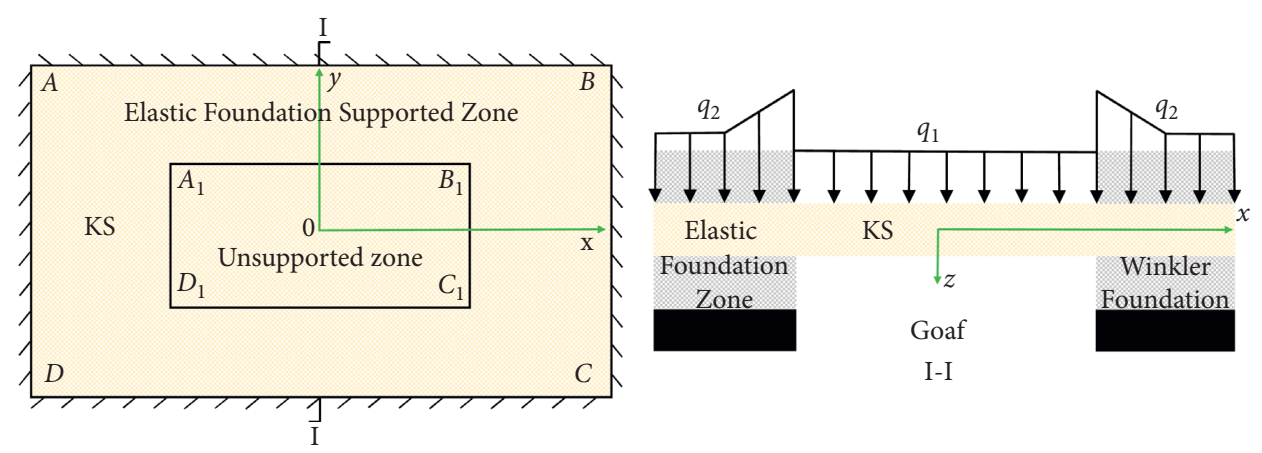

Figure 3: Mechanical model of first fracture.

$$
\begin{aligned}
& \frac{\partial^{4} w_{1}}{\partial x^{4}}+2 \frac{\partial^{4} w_{1}}{\partial x^{2} \partial y^{2}}+\frac{\partial^{4} w_{1}}{\partial y^{4}}=\frac{q_{1}}{D}, \\
& \frac{\partial^{4} w_{2}}{\partial x^{4}}+2 \frac{\partial^{4} w_{2}}{\partial x^{2} \partial y^{2}}+\frac{\partial^{4} w_{2}}{\partial y^{4}}+\frac{k w_{2}}{D}=\frac{q_{2}}{D},
\end{aligned}
$$

where $w_{1}$ and $w_{2}$ are the deflection function of unsupported zone and elastic foundation-supported zone and $D$ is the flexural rigidity of $\mathrm{KS}, \mathrm{GPa} \cdot \mathrm{m}^{3}$.
In order to characterize the movement and deformation of elastic foundation, introducing the Winkler foundation model, the foundation modulus $k$ is as follows $[6,30]$ :

$$
\frac{1}{k}=\frac{1}{k_{c}}+\frac{1}{k_{i}},
$$

where $k_{c}$ and $k_{i}$ are the elastic coefficients of coal seam and other strata, $\mathrm{GPa} / \mathrm{m}$.

The load $q_{1}$ of the unsupported zone is as follows [25]: 


$$
q_{1}=\frac{E_{1} \delta_{1}^{3}\left(\gamma_{1} \delta_{1}+\gamma_{2} \delta_{2}+\cdots+\gamma_{n} \delta_{n}\right)}{E_{1} \delta_{1}^{3}+E_{2} \delta_{2}^{3}+\cdots+E_{n} \delta_{n}^{3}},
$$

where $\delta_{1}, \delta_{2}, \ldots, \delta_{n}$ are the thickness of the KS and controlled rock strata, $\mathrm{m} ; \gamma_{1}, \gamma_{2}, \ldots, \gamma_{n}$ are the volume force of the KS and controlled rock strata, $\mathrm{MN} / \mathrm{m}^{3}$; and $E_{1}, E_{2}, \ldots, E_{n}$ are the elastic modulus of the KS and controlled rock strata, GPa.

The transfer load of the elastic foundation support area can be obtained by inversion of its subsidence value [30]. The load $q_{2}$ of elastic foundation-supported zone is as follows:

$$
q_{2}=k w+\gamma H_{d}
$$

where $w$ is the subsidence value of the elastic foundation, $\mathrm{m}$; $\gamma$ is the average volume force of overburden, $\mathrm{MN} / \mathrm{m}^{3}$; and $H_{d}$ is the depth of $\mathrm{KS}, \mathrm{m}$.

The differential equations of the fixed boundary conditions are as follows [30]:

$$
\left\{\begin{array}{l}
A B\left\{w_{2}=0 \frac{\partial w_{2}}{\partial y}=0\right. \\
C D\left\{w_{2}=0 \frac{\partial w_{2}}{\partial y}=0\right. \\
A D\left\{w_{2}=0 \frac{\partial w_{2}}{\partial x}=0\right. \\
B C\left\{w_{2}=0 \frac{\partial w_{2}}{\partial x}=0\right.
\end{array}\right.
$$

2.2. Mechanical Model of KS Periodic Fracture. When the KS first fractures, with the excavation of the longwall panel, the KS will fracture periodically; the mechanical model is shown in Figure 4. The $C_{1} D_{1}$ of the unsupported zone and the $D_{1} D_{2}$ and $C_{1} C_{2}$ of goaf are free boundaries. Other boundaries of the unsupported zone are clamped boundary conditions. The load of the unsupported zone is $q_{1}$, which is the sum of self-weight and controlled weak rock strata load. The elastic foundation-supported zone load is $q_{2}$, which is the sum of the transfer load of the unsupported zone and the field stress.

The differential equations of the free boundary conditions are as follows:

$$
\left\{\begin{array}{l}
D_{1} D_{2}\left\{\frac{\partial^{2} w_{2}}{\partial x^{2}}+\mu \frac{\partial^{2} w_{2}}{\partial y^{2}}=0 \frac{\partial^{3} w_{2}}{\partial x^{3}}+(2-\mu) \frac{\partial^{3} w_{2}}{\partial y^{2} \partial x}=0\right. \\
C_{1} D_{1}\left\{\frac{\partial^{2} w_{1}}{\partial y^{2}}+\mu \frac{\partial^{2} w_{1}}{\partial x^{2}}=0 \frac{\partial^{3} w_{1}}{\partial y^{3}}+(2-\mu) \frac{\partial^{3} w_{1}}{\partial x^{2} \partial y}=0\right. \\
C_{1} C_{2}\left\{\frac{\partial^{2} w_{2}}{\partial x^{2}}+\mu \frac{\partial^{2} w_{2}}{\partial y^{2}}=0 \frac{\partial^{3} w_{2}}{\partial x^{3}}+(2-\mu) \frac{\partial^{3} w_{2}}{\partial y^{2} \partial x}=0\right.
\end{array}\right.
$$

2.3. Differential Equation Solution Method: Finite Difference Method. It is challenging to acquire the unified functional expression because the basic differential equations of the unsupported zone and the elastic foundation-supported zone are different. The finite difference method uses difference equations to express the differential equations $[9,30,31]$. Finite difference grid is shown in Figure 5; the intersection of the grid is called the node with equal spacing $h$. Using MATLAB software to solve the difference equations can get the deflection value of each node [30-32]. The solving process is shown in Figure 6. The stress value of each node is calculated according to the deflection value.

The principal stress calculation equation of $x y$ plane is as follows [33]:

$$
\sigma_{\sigma_{3}}^{\sigma_{1}}=\frac{\sigma_{x}+\sigma_{y}}{2} \pm \sqrt{\left(\frac{\sigma_{x}-\sigma_{y}}{2}\right)^{2}+\tau_{x y}^{2}},
$$

where $\sigma_{1}$ is the major principal stress $(\mathrm{MPa})$ and $\sigma_{3}$ is the minor principal stress $(\mathrm{MPa})$. The principal stress equations for the $x z$ plane and $y z$ plane are the same as equation (7) and are no longer listed.

\section{Fracture Characteristics of KS and Overburden Zoning Model}

3.1. Stress Distribution of KS First Fracture. To eliminate the boundary effect, the $x$-axis length of the KS first fracture model is $400 \mathrm{~m}$, and the $y$-axis length of the KS first fracture model is $250 \mathrm{~m}$. The $x$-axis length of the KS periodic fracture model is $400 \mathrm{~m}$. The $y$-axis length of the $\mathrm{KS}$ periodic fracture model is $120 \mathrm{~m}$. The calculation parameters of the unsupported zone are selected according to the size of the general longwall mining panel. The longwall panel length is $200 \mathrm{~m}$. The excavation length of the KS first fracture model is $50 \mathrm{~m}$. The excavation length of the KS periodic fracture model is $20 \mathrm{~m}$. The grid spacing $h$ is $1 \mathrm{~m}$. The KS elastic modulus is $5 \mathrm{GPa}$, thickness is $10 \mathrm{~m}$, Poisson ratio is 0.32 , load $q_{1}$ is $0.5 \mathrm{MPa}$, and foundation modulus is $200 \mathrm{MN} / \mathrm{m}^{3}$. We analyzed the KS major stress distribution characteristics in the plane and section under the condition of elastic foundation support.

The major principal stress distribution at the upper surface of the $x y$ plane of the KS first fracture model is shown in Figure 7. The stress range of KS is larger than the mining area. The middle of the unsupported zone is subjected to compressive stress. The area around the elastic foundationsupported zone is subjected to tensile stress. The maximum tensile stress is close to the junction of two zones and is located above the coal seam (rock strata) around the goaf, called advanced tensile stress. The stress direction of the advanced tensile stress distributed along the $x$-axis is perpendicular to the $x$-axis. The stress direction of the advanced tensile stress distributed along the $y$-axis is perpendicular to the $y$-axis, as shown in Figure 7.

The major principal stress distribution at the lower surface of the $x y$ plane of the KS first fracture model is shown in Figure 8. The middle of the unsupported zone is subjected 


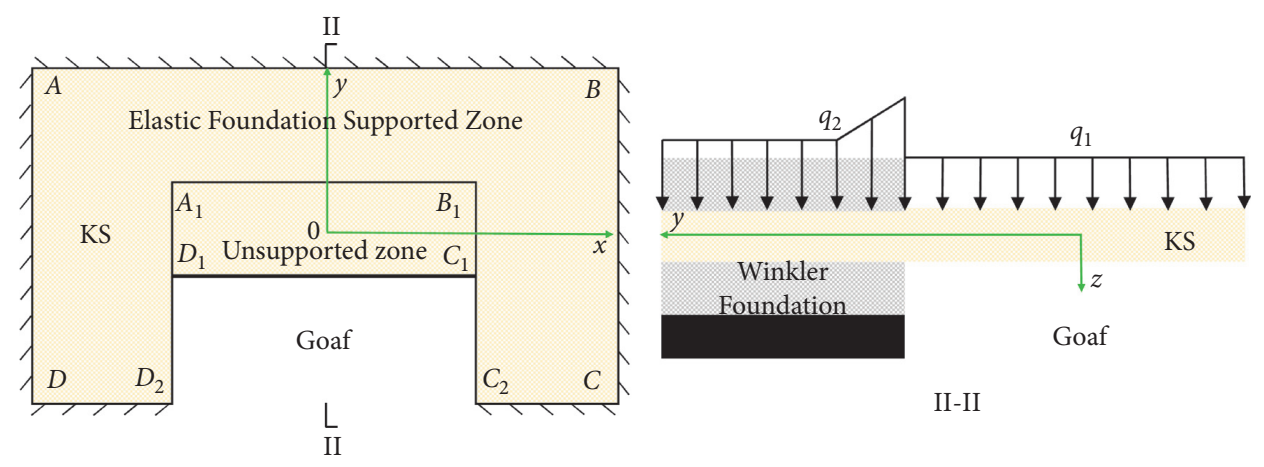

FIgURE 4: Mechanical model of periodic fracture.

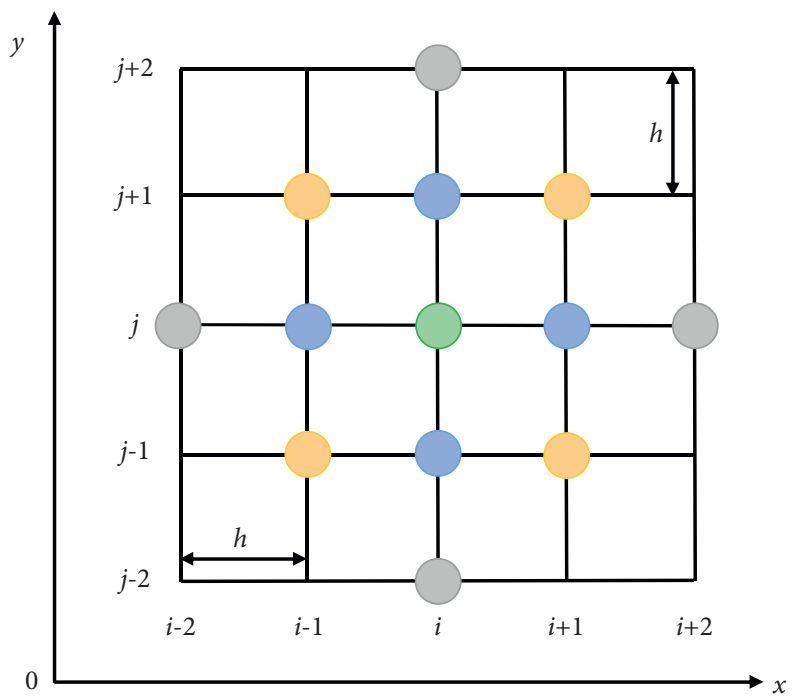

FIGURE 5: Finite difference grid.

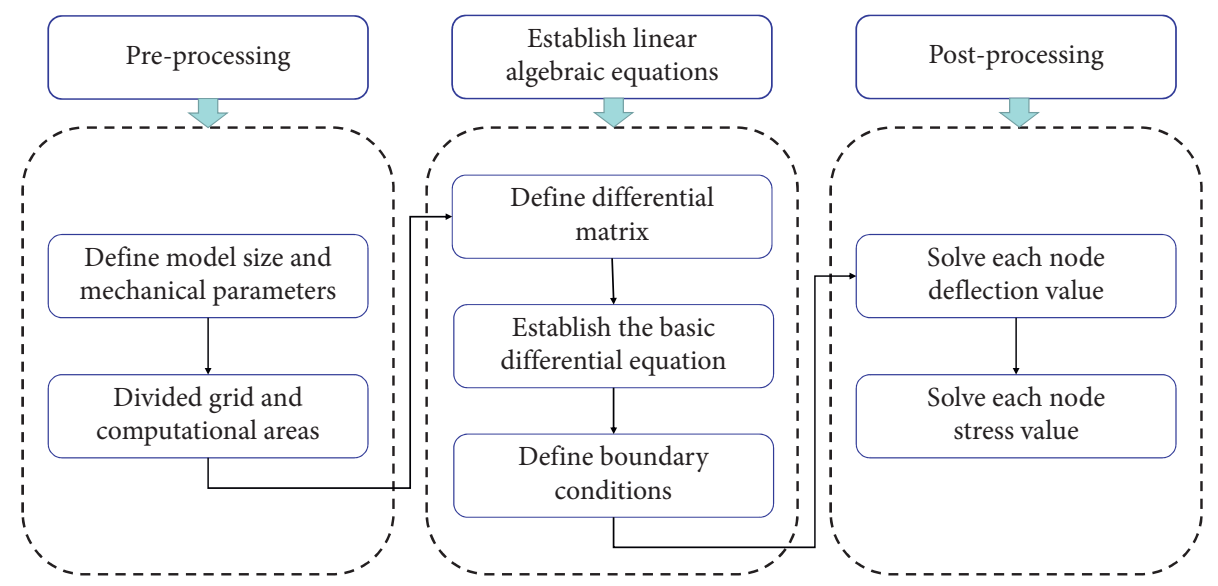

Figure 6: Finite difference solving process.

to tensile stress. The area around the elastic foundationsupported zone is subjected to compressive stress. The maximum tensile stress is located in the middle of the lower surface of the unsupported zone, which is called the middle tensile stress. When the middle tensile stress contour is decreased to the periphery, it is deflected in the four corner regions. The stress direction of the tensile stress in the middle of the lower surface of the unsupported area is parallel to the $x$-axis. The stress direction of the tensile stress near the coal wall deflects to the corner, as shown in Figure 8.

The KS first fracture model's major principal stress distribution on $x z$ and $y z$ sections is shown in Figures 9 and 10 . 


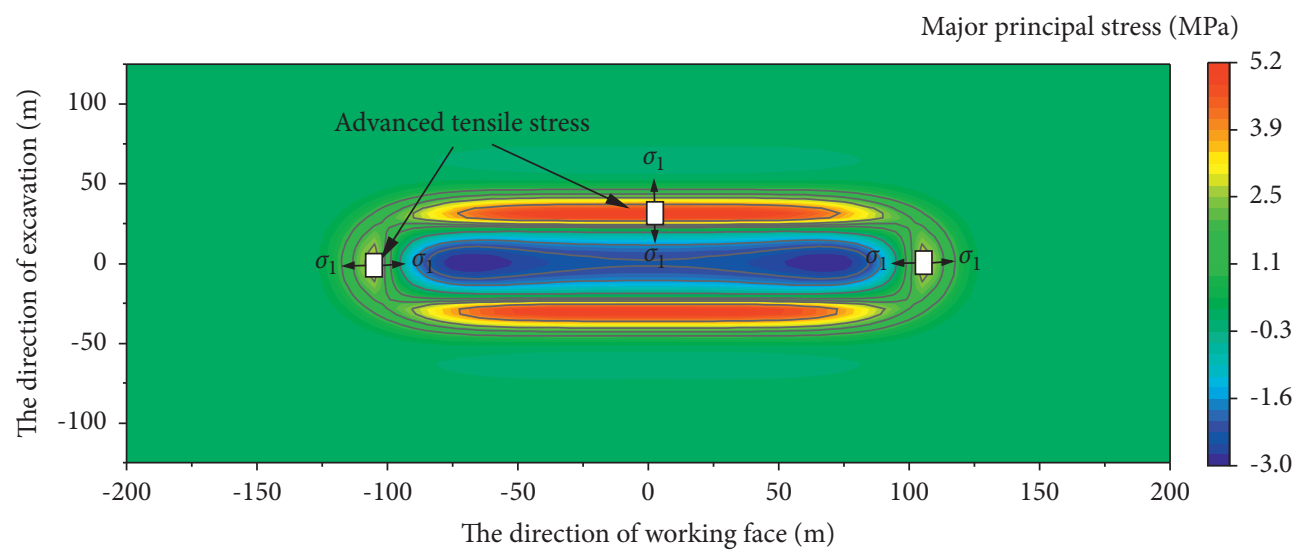

FIgURE 7: Major principal stress at the upper surface on $x y$ plane of first fracture model.

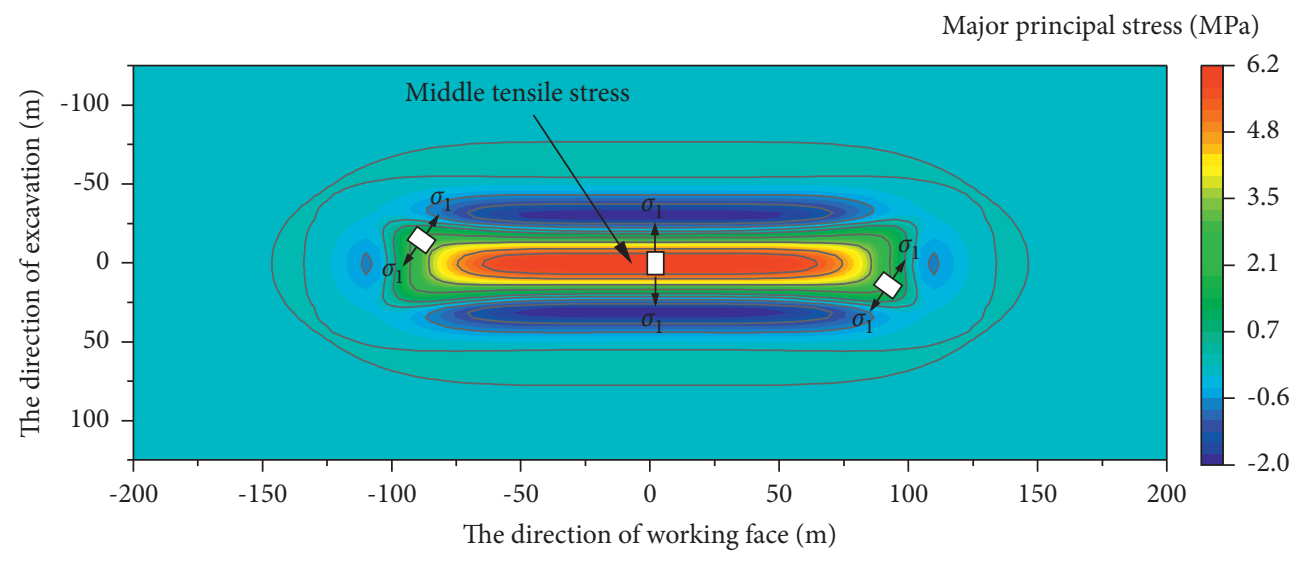

FIGURE 8: Major principal stress at the lower surface on $x y$ plane of first fracture model.

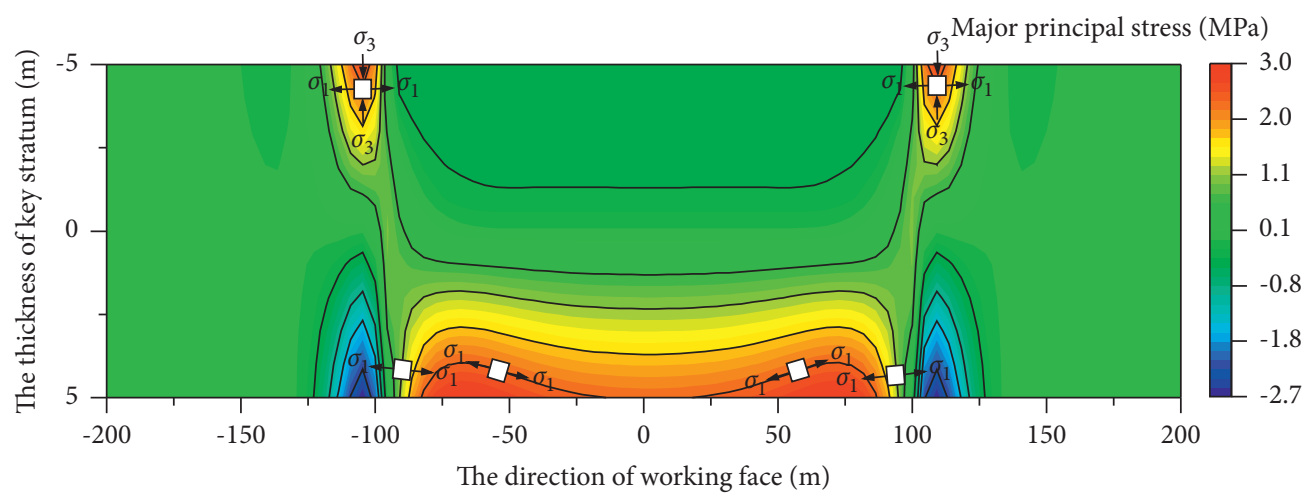

FIGURE 9: Major principal stress on $x z$ section of first fracture model.

The elastic foundation-supported zone is subjected to tensile stress on the upper surface and compressive stress on the lower surface. The unsupported zone is subjected to compressive stress on the upper surface and tensile stress on the lower surface. The maximum tensile stress at the lower surface of the unsupported zone of the $x z$ section is located on both sides of the $x$-axis center. The maximum tensile stress at the lower surface of the unsupported zone of the $y z$ section is located at the $y$-axis center. The tensile-compression stress transition line near the coal wall deflects to the goaf. According to elasticity, the vertical stress of elastic foundation-supported zone increases gradually from top to bottom. The vertical stress of the unsupported zone decreases gradually from top to bottom. Therefore, the upper surface of the elastic foundationsupported zone is in the biaxial compressive-tensile state, and the lower surface of the unsupported zone is in the uniaxial tensile state. 


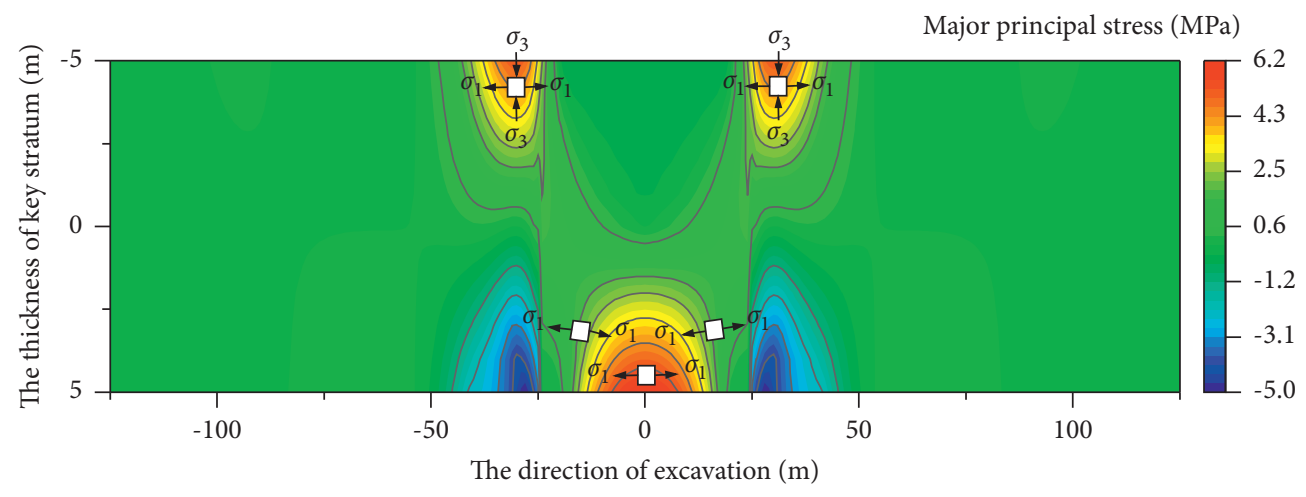

FIGURE 10: Major principal stress on $y z$ section of first fracture model.

3.2. Stress Distribution of KS Periodic Fracture. The major principal stress distribution at the upper surface of the $x y$ plane of the KS periodic fracture model is shown in Figure 11. The stress range of KS is also larger than the mining area. The middle of the unsupported zone is subjected to compressive stress. The area around the elastic foundation-supported zone is subjected to tensile stress. The advanced tensile stress is close to the junction of two zones and is located in front of the longwall panel and two corners of the free boundary. The stress direction of the advanced tensile stress in front of the longwall panel is perpendicular to the $x$-axis and points to the goaf. The stress direction of the tensile stress in the two corners of the free boundary deflects to the inner side of the coal wall, as shown in Figure 11.

The major principal stress distribution at the lower surface of the $x y$ plane of the KS periodic fracture model is shown in Figure 12. The middle of the unsupported zone is subjected to tensile stress. The elastic foundation-supported zone in front of the longwall panel is subjected to compressive stress. The maximum tensile stress is located at the free boundary of the unsupported zone's lower surface and central symmetric distribution along the $x$-axis. The contour line of edge tensile stress deflects to the corner on both sides of the longwall panel. The transition line of tensile and compressive stress near the coal wall deflects to the center, as shown in Figure 12.

The KS periodic fracture model's major principal stress distribution on $x z$ and $y z$ sections is shown in Figures 13 and 14. The elastic foundation-supported zone is subjected to tensile stress on the upper surface and compressive stress on the lower surface. The unsupported zone is subjected to compressive stress on the upper surface and tensile stress on the lower surface. The maximum tensile stress at the lower surface of the unsupported zone of the $x z$ section is located on both sides of the $x$-axis center. The tensile-compressive stress transition line near the coal wall deflects to the center. The maximum tensile stress at the upper surface of the $y z$ section is located in the elastic foundation-supported zone and gradually decreases to the unsupported zone. The tensile-compressive stress transition line near the coal wall deflects obliquely. Therefore, the upper surface of the elastic foundationsupported zone and the unsupported zone is in the biaxial compressive-tensile state. The lower surface of the unsupported zone is in the uniaxial tensile state.

3.3. KS Fracture Characteristics. According to the stress distribution law of KS and the Mohr-Coulomb strength criterion, the fracture positions of the KS are mainly concentrated in the upper surface of the elastic foundationsupported zone near the goaf boundary, the middle of the lower surface of the unsupported zone, and the lower zone of the unsupported zone near the coal wall. According to the Mohr-Coulomb strength criterion, when the normal stress is compressive, shear yield will occur in the KS. When the normal stress is tensile, tensile yield will occur in the KS [33]. As shown in Figures 15 and 16, the upper surface of the elastic foundation-supported zone near the coal wall is in the biaxial compressive-tensile stress state. The shear fracture is easy to occur. Since the end and center of the lower surface of the unsupported zone are in the uniaxial tensile state, the tensile fracture is easy to occur. In order to distinguish different forms of fracture, green is used to represent shear fracture, and blue is used to represent tensile fracture.

The KS first fracture characteristics are shown in Figure 15. In section I-I, the shear slip line of the upper surface of the elastic foundation-supported zone extends obliquely below the coal wall. The tensile fracture line of the middle of the lower surface of the unsupported zone extends vertically upward. After the KS's fracture, the boundary conditions of KS change, and the stress will transfer, increasing the tensile stress near the coal wall in the unsupported zone. The tensile fracture line expands obliquely along the tensile-compressive transition line. The above fracture characteristics have been confirmed in two-dimensional numerical simulation and similar simulation or field measurement [27, 34-38]. In section II-II, the maximum tensile stress of the lower surface of the unsupported zone is symmetrically distributed along the centerline. With the bending and sinking of KS, the tensile fracture line extends obliquely upward.

According to the stress distribution law, we can distinguish the first fracture sequence of KS according to the stress distribution characteristics. The first fracture position of the KS is the upper surface of the elastic foundationsupported zone parallel to both sides of the longwall panel and the center of the lower surface of the unsupported zone. 


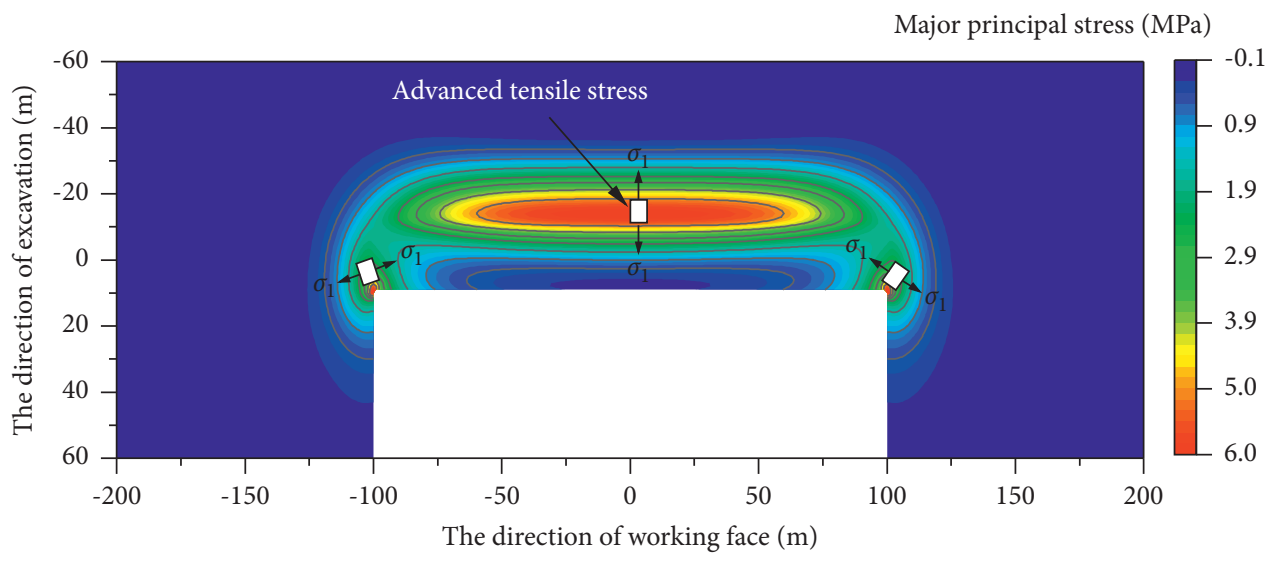

Figure 11: Major principal stress at the upper surface on $x y$ plane of periodic fracture model.

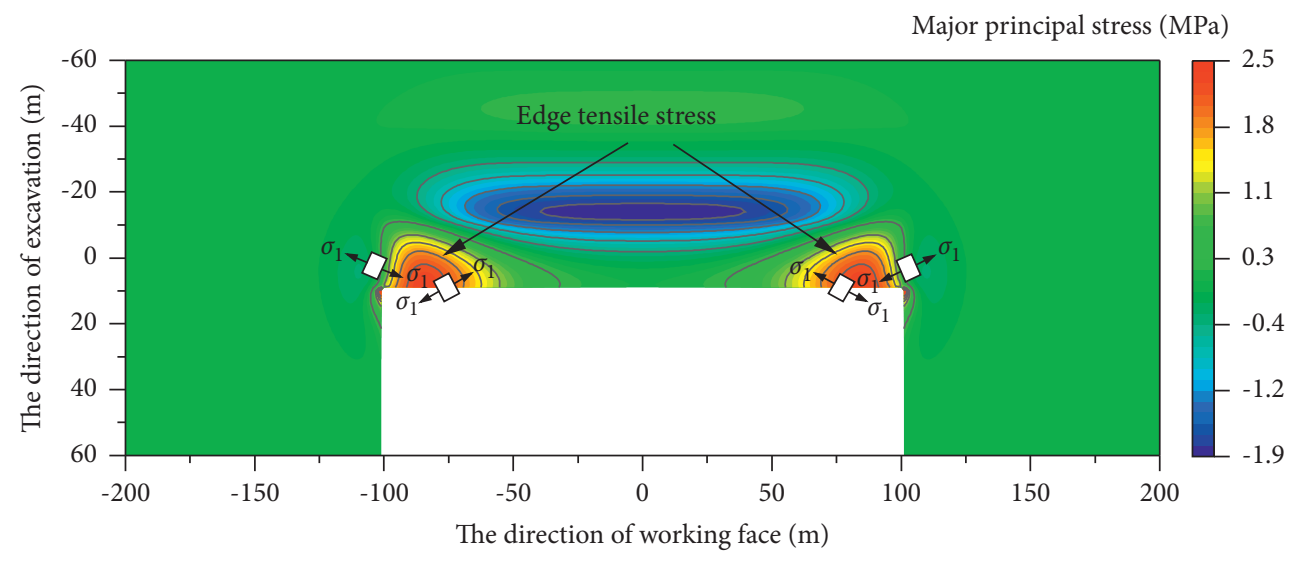

FIGURE 12: Major principal stress at the lower surface on $x y$ plane of periodic fracture model.

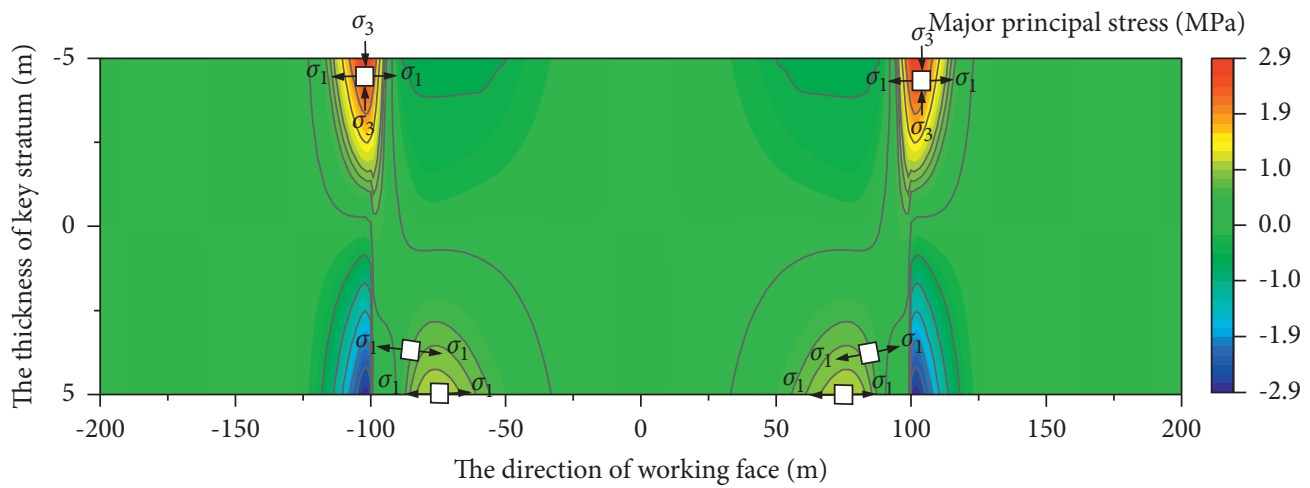

FIGURE 13: Major principal stress on $x z$ section of periodic fracture model.

The crack expansion direction is parallel to the longwall panel. Then, the elastic foundation-supported zone is parallel to the excavation direction fracture. The crack expansion direction is parallel to the excavation direction. When the fractures around the elastic foundation-supported zone are connected in the corner, an "O" shaped interconnected fracture will form. When the crack in the middle of the lower surface of the unsupported zone expands to the coal wall on both sides, the crack expansion direction deflects at the corner. It forms an " $\mathrm{X}$ " shaped fracture. In the end, the oblique tensile interconnected fracture occurs around the unsupported zone near the coal wall, forming an "O" shaped interconnected fracture. Finally, the KS forms a double "O-X" shaped interconnected fracture zone after the first fracture, as shown in Figure 15. The internal "O-X" shaped fracture characteristics have been confirmed in 


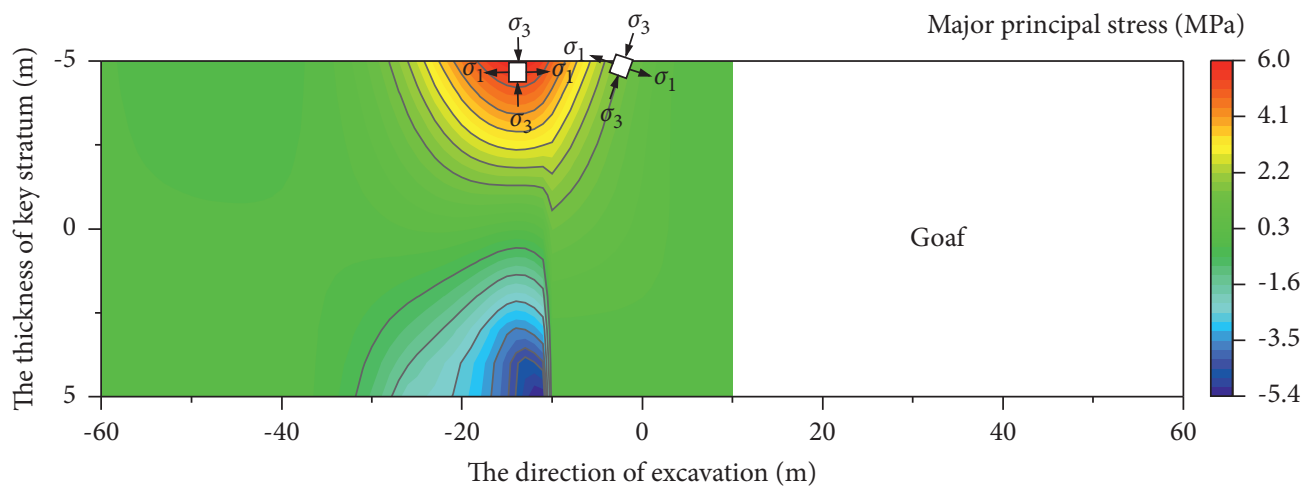

Figure 14: Major principal stress on $y z$ section of periodic fracture model.
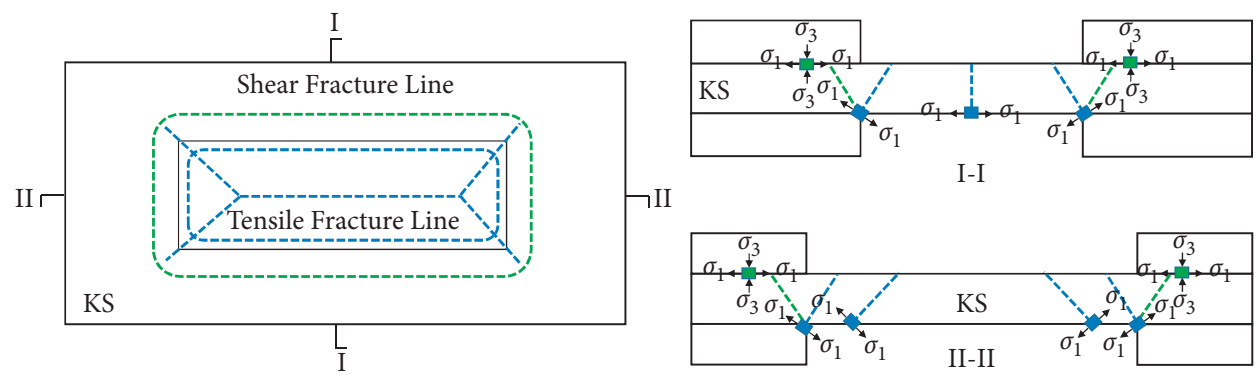

II

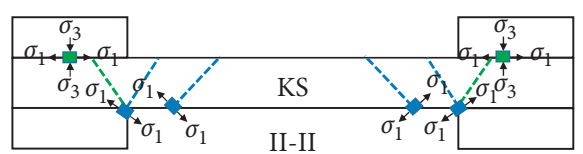

FIGURE 15: KS first fracture characteristics.
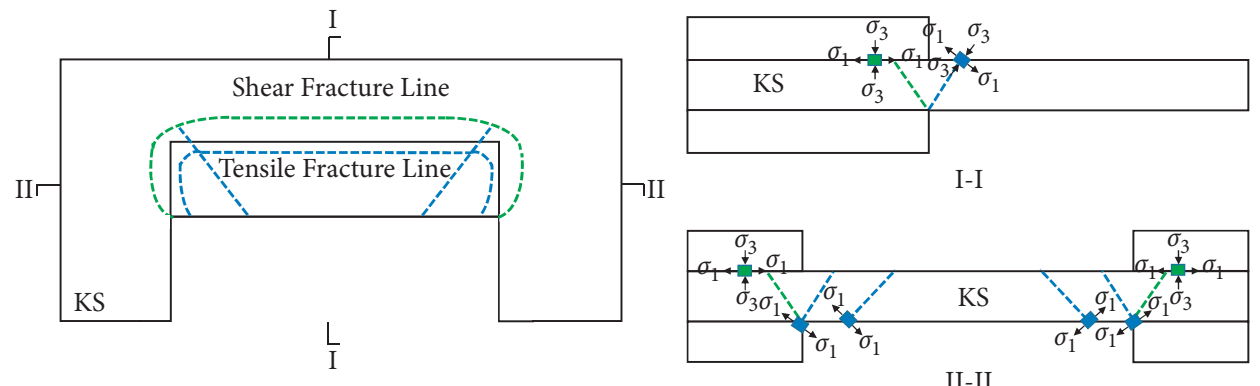

FIGURE 16: KS periodic fracture characteristics.

three-dimensional simulation experiments $[6,39,40]$. However, the similarity ratio of the three-dimensional simulation is relatively large, and it is difficult to observe the tiny shear fractures of the rock strata above the coal pillar [34].

The KS periodic fracture characteristics are shown in Figure 16. In section I-I, the shear slip line of the upper surface of the elastic foundation-supported zone extends obliquely below the coal wall. After the KS's fracture, the boundary conditions of KS change, and the stress will transfer, increasing the tensile stress near the coal wall in the unsupported zone. The tensile fracture line expands obliquely along the tensile-compressive transition line. The above fracture characteristics have also been confirmed in two-dimensional numerical simulation and similar simulation or field measurement [27, 34-38]. The fracture characteristics in section II-II are the same as those in the KS first fracture.

According to the stress distribution law, we can distinguish the periodic fracture sequence of KS according to the stress distribution characteristics. The first fracture position of the KS is the upper surface of the elastic foundation-supported zone in front of the longwall panel and the corner regions of the free boundary. The crack expansion direction of the elastic foundation-supported zone is parallel to the longwall panel. The crack in the corner regions of the free boundary extends obliquely to the inside of the coal wall. It is connected with the crack in the elastic foundation-supported zone to form a "C" shaped interconnected fracture. Then, the cracks in the two edges' tensile stress concentration area of the free boundary deflect to the two corner regions of the longwall panel, 


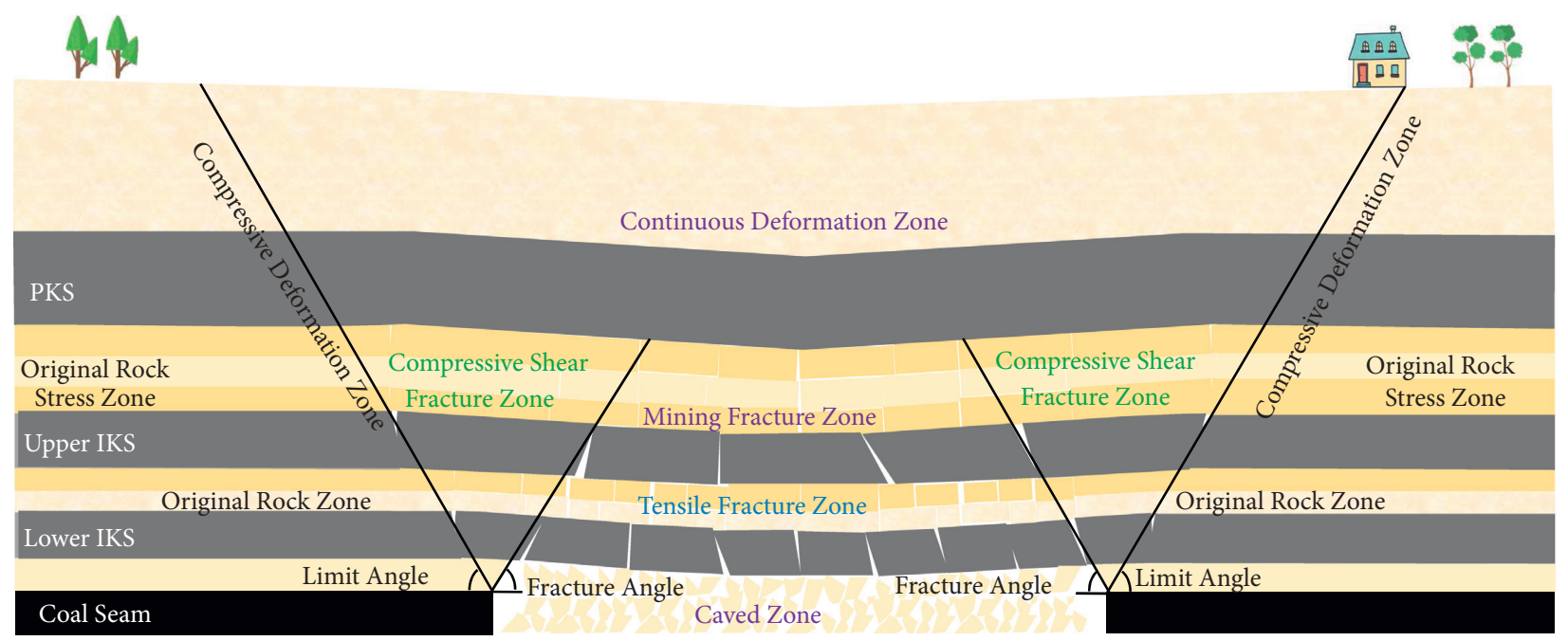

FIgURE 17: Fracture characteristics and zoning model of overburden.

forming a " $\mathrm{K}$ " shaped fracture. In the end, the oblique tensile interconnected fracture occurs around the unsupported zone near the coal wall, forming a " $C$ " shaped interconnected fracture. Finally, the KS forms a double "C$\mathrm{K}$ ” shaped interconnected fracture zone after periodic fracture, as shown in Figure 16. The internal " $\mathrm{C}-\mathrm{K}$ " shaped fracture characteristics have been confirmed in three-dimensional simulation experiments [6].

3.4. Zoning Model of Overburden. According to the KS's fracture mechanism, the KS can be divided into three zones: compressive shear fracture zone, tensile fracture zone, and original rock zone. The shear fracture zone is distributed in the elastic foundation-supported zone near the goaf. Due to the clamping of the upper and lower strata, the large-scale movement generally does not occur, and the rock mass remains continuous. The tensile fracture zone is distributed in the unsupported zone. Due to the lack of effective support, large-scale movement will be formed in the process of strata movement, and the integrity of rock mass cannot be maintained. Both sides of the shear fracture zone are original rock zones.

Strata movement is the whole movement behavior from overburden to surface above goaf after coal mining. Taking three groups of $\mathrm{KS}$ in the overburden as an example, we analyzed the zoning characteristics of mining-induced overburden movement. After the lower IKS's fracture, the plastic displacement occurs in the compression-shear fracture zone. As the elastic foundation of the upper IKS, its supporting capacity is weakened. The elastic foundation thickness of the upper IKS increases, the foundation modulus decreases, and the supporting capacity decreases. As a result, the compressive shear fracture zone of the upper IKS increases, and the fracture range expands to the outside. The oblique tensile fracture near the coal wall of the lower IKS causes the support range of the upper IKS to increase and the tensile fracture range to decrease. The tensile fracture trace of the overburden shows an inverted step shape from bottom to top.
During longwall mining, the zoning characteristics of overburden above the goaf are shown in Figure 17. In the direction vertical to the goaf, according to the degree of overburden fracture, it is divided into three zones: caving zone, mining fracture zone, and continuous deformation zone. In the direction parallel to the goaf, the overburden is divided into three zones: original rock zone, compressive shear fracture zone, and tensile fracture zone. The strata movement boundary bounds the original rock zone and compressive shear fracture zone. The tensile fracture line of rock strata bounds the compressive shear fracture zone and tensile fracture zone. The compressive shear fracture zone is approximately inverted triangle distribution. The tensile fracture zone is approximately trapezoidal, with inclined interconnected fractures and horizontal cracks $[22,41]$. The rock strata in the fracture zone form a trapezoidal block fracture. A biting relationship exists between rock blocks, forming a "voussoir beam" balanced structure [15]. When the rock beam structure is unstable, the fracture zone will be transformed into the caving zone. When the coal seam is buried shallowly, the PKS's fracture will lead to surface step subsidence [42].

\section{Conclusions}

(1) Considering the elastic supporting effect of coal and rock mass, we established a KS's mining-induced mechanics model. Before the KS's first fracture, the upper surface of the elastic foundation-supported zone was in a compressive-tensile stress state. The middle of the lower surface of the unsupported zone was in a tensile stress state. Before the KS's periodic fracture, the upper surface of the elastic foundationsupported zone was in a compressive-tensile stress state. The free boundary of the KS's lower surface was in a tensile stress state.

(2) According to the stress distribution of the KS, we obtained the KS's fracture shape. After the KS's first fracture, the elastic foundation-supported zone formed an "O" shaped interconnected shear fracture. 
The unsupported zone formed an "O-X" shaped interconnected tensile fracture. After the KS's periodic fracture, the elastic foundation-supported zone formed a "C" shaped interconnected shear fracture. The unsupported zone formed a "C-K" shaped interconnected tensile fracture.

(3) According to the KS's fracture mechanism, we established an overburden zoning model. The overburden above goaf was divided into three zones along the horizontal direction: the original rock area, the compressive shear fracture zone, and the tensile fracture zone. The overburden's zoning model reveals the tensile fracture mechanism of the inverted step shape in the mining fracture zone and explains the shear fracture mechanism of the inverted triangle in the coal pillar supporting zone.

\section{Data Availability}

The data used to support the findings of this study are included within the article.

\section{Conflicts of Interest}

The authors declare that they have no conflicts of interest.

\section{Acknowledgments}

This work was supported by the Engineering Laboratory of Deep Mine Rockburst Disaster Assessment Open Project (LMYK2021001) and the Heilongjiang Natural Science Fund for Excellent Young Scholars Project (YQ2019E033).

\section{References}

[1] S. S. Peng, Longwall Mining, CRC Press/Balkema, London, UK, 3rd edition, 2019.

[2] S. S. Peng, Advances in Coal Mine Ground Control, Woodhead, Duxford, UK, 2017.

[3] H. Guo, L. Yuan, B. Shen, Q. Qu, and J. Xue, "Mining-induced strata stress changes, fractures and gas flow dynamics in multi-seam longwall mining," International Journal of Rock Mechanics and Mining Sciences, vol. 54, pp. 129-139, 2012.

[4] Y. Chen, G. Zhao, S. Wang, and X. Li, "Investigations of the height of fractured zones in overburden induced by undersea mining," Arabian Journal of Geosciences, vol. 12, no. 19, pp. 618-630, 2019.

[5] J. P. Zuo, Y. J. Sun, and M. G. Qian, "Movement mechanism and analogous hyperbola model of overburden with thick alluvium," Journal of China Coal Society, vol. 42, no. 6, pp. 1372-1379, 2017.

[6] F. L. He, J. S. Zhao, and Z. C. Yao, Control Theory of Stope Rock Strata, Metallurgical Industry Press, Beijing, China, 2009.

[7] M. G. Qian, P. W. Shi, and J. L. Xu, Ground Pressure and Strata Control, China University of Mining and Technology Press, Xuzhou, China, 2010.

[8] L. Jiang, Q. Wu, Q. Wu et al., "Fracture failure analysis of hard and thick key layer and its dynamic response characteristics," Engineering Failure Analysis, vol. 98, pp. 118-130, 2019.

[9] D. Chen, X. Wu, S. Xie et al., "Study on the thin plate model with elastic foundation boundary of overlying strata for backfill mining," Mathematical Problems in Engineering, vol. 2020, Article ID 8906091, 15 pages, 2020.

[10] J. P. Zuo, Y. J. Sun, J. T. Wang, Y. Shi, and J. Wen, “"Mechanical and numerical analysis of "analogous hyperbola" movement of overburden after full mining extraction," Journal of Mining and Safety Engineering, vol. 35, no. 1, pp. 71-77, 2018.

[11] Y. Sun, J. Zuo, M. Karakus, and J. Wang, "Investigation of movement and damage of integral overburden during shallow coal seam mining," International Journal of Rock Mechanics and Mining Sciences, vol. 117, pp. 63-75, 2019.

[12] J. P. Zuo, G. S. Wu, Y. J. Sun, and M. Yu, "Investigation on the inner and outer analogous hyperbola model (AHM) of strata movement," Journal of China Coal Society, vol. 46, no. 2, pp. 333-343, 2021.

[13] D. Xu, S. Peng, S. Xiang, and Y. He, “A novel caving model of overburden strata movement induced by coal mining," Energies, vol. 10, no. 4, pp. 476-489, 2017.

[14] W. Guo, G. Zhao, and G. Wang, "A new method of predicting the height of the fractured water-conducting zone due to high-intensity longwall coal mining in China," Rock Mechanics and Rock Engineering, vol. 52, no. 8, pp. 2789-2802, 2019.

[15] M. G. Qian and H. C. Li, "The movement of overburden in longwall mining and its effect on ground pressure," Journal of China Coal Society, vol. 2, pp. 1-12, 1982.

[16] A. Karaman, T. Seyhan, and M. F. Işık, "Detecting the footprint of a longwall mine panel claimed to infringe on a permit boundary at the Soma-Darkale coalfield (Manisa, Turkey) using surface fractures and microgravity measurements," Environmental earth sciences, vol. 70, no. 4, pp. 1895-1902, 2013.

[17] B. Yu, J. Zhao, and H. Xiao, "Case study on overburden fracturing during longwall top coal caving using microseismic monitoring," Rock Mechanics and Rock Engineering, vol. 50, no. 2, pp. 507-511, 2017.

[18] G. Cheng, T. Yang, H. Liu et al., "Characteristics of stratum movement induced by downward longwall mining activities in middle-distance multi-seam," International Journal of Rock Mechanics and Mining Sciences, vol. 136, Article ID 104517, 2020.

[19] T. Chen, S. M. Wang, and Y. Wang, "Study on the distribution of microseismic activities caused by longwall mining," Journal of Mining and Safety Engineering, vol. 35, no. 4, pp. 795-800, 2018.

[20] B. Yu, J. Zhao, T. J. Kuang, and X. Meng, "In situ investigations into overburden failures of a super-thick coal seam for longwall top coal caving," International Journal of Rock Mechanics and Mining Sciences, vol. 78, 2015.

[21] X. Shi, X. Zhang, and F. Jiang, "A case study of fracture law and stress distribution characteristics of surrounding rock of working face in deep mines," Geotechnical \& Geological Engineering, vol. 37, no. 4, pp. 2935-2948, 2019.

[22] V. Palchik, "Formation of fractured zones in overburden due to longwall mining," Environmental Geology, vol. 44, no. 1, pp. 28-38, 2003.

[23] N. Hosseini, K. Oraee, K. Shahriar, and K. Goshtasbi, "Studying the stress redistribution around the longwall mining panel using passive seismic velocity tomography and geostatistical estimation," Arabian Journal of Geosciences, vol. 6, no. 5, pp. 1407-1416, 2013.

[24] G. Cheng, T. Ma, C. Tang, H. Liu, and S. Wang, “A zoning model for coal mining-induced strata movement based on microseismic monitoring," International Journal of Rock Mechanics and Mining Sciences, vol. 94, pp. 123-138, 2017. 
[25] M. G. Qian, X. X. Liao, and J. L. Xu, Key Strata Theory in Ground Control, China University of Mining and Technology Press, Xuzhou, China, 2000.

[26] Y. Lan, R. Gao, B. Yu, and X. Meng, "In situ studies on the characteristics of strata structures and behaviors in mining of a thick coal seam with hard roofs," Energies, vol. 11, no. 9, p. 2470,2018

[27] F. Du, K. Jiao, and Z. Ma, "Influence of key strata on the gas downward leakage law in dual-system of coal seam," Geofluids, vol. 2020, Article ID 8897260, 10 pages, 2020.

[28] J. L. Xu, W. B. Zhu, and X. Z. Wang, "New method to predict the height of fractured water-conducting zone by location of key strata," Journal of China Coal Society, vol. 37, no. 5, pp. 762-769, 2012.

[29] J. L. Xu, Distribution Law of Mining-Induced Strata Fractures and its Applications, China University of Mining and Technology Press, Xuzhou, China, 2016.

[30] Z. Ti, J. Li, M. Wang, K. Wang, Z. Jin, and C. Tai, "Fracture mechanism in overlying strata during longwall mining," Shock and Vibration, vol. 2021, Article ID 4764732, 15 pages, 2021.

[31] Z. L. Xu, Elasticity, Higher Education Press, Beijing, China, 2006.

[32] X. Zhang, Efficient Solution of Differential Equations in MATLAB: Principle and Realization of Spectrum Method, China Machine Press, Beijing, China, 2016.

[33] H. M. Yu, Y. W. Zan, and S. Q. Xu, Rock Strength Theory and its Application, China Science Press, Beijing, China, 2017.

[34] Y. Ju, Y. Wang, C. Su, D. Zhang, and Z. Ren, "Numerical analysis of the dynamic evolution of mining-induced stresses and fractures in multilayered rock strata using continuumbased discrete element methods," International Journal of Rock Mechanics and Mining Sciences, vol. 113, pp. 191-210, 2019.

[35] B. Ghabraie, G. Ren, and J. V. Smith, "Characterising the multi-seam subsidence due to varying mining configuration, insights from physical modelling," International Journal of Rock Mechanics and Mining Sciences, vol. 93, pp. 269-279, 2017.

[36] Y. Xu, K. Wu, L. Li, D. Zhou, and Z. Hu, "Ground cracks development and characteristics of strata movement under fast excavation: a case study at Bulianta coal mine, China," Bulletin of Engineering Geology and the Environment, vol. 78, no. 1, pp. 325-340, 2019.

[37] G. Zhang, G. Guo, Y. N. Lv, and Y. Gong, "Study on the strata movement rule of the ultrathick and weak cementation overburden in deep mining by similar material simulation: a case study in China," Mathematical Problems in Engineering, vol. 2020, Article ID 7356740, 21 pages, 2020.

[38] T. Hu, G. Hou, and Z. Li, "The field monitoring experiment of the roof strata movement in coal mining based on DFOS," Sensors, vol. 20, no. 5, pp. 1318-1350, 2020.

[39] J. P. Zuo, M. L. Yu, and S. Y. Hu, "Experimental investigation on fracture mode of different thick rock strata," Journal of Mining and Strata Control Engineering, vol. 1, no. 1, pp. 88-96, 2019.

[40] J. Zuo, M. Yu, C. Li, Y. Sun, S. Hu, and Z. Li, "Analysis of surface cracking and fracture behavior of a single thick main roof based on similar model experiments in western coal mine, China," Natural Resources Research, vol. 30, no. 1, pp. $657-680,2020$.

[41] V. Palchik, "Localization of mining-induced horizontal fractures along rock layer interfaces in overburden: field measurements and prediction," Environmental Geology, vol. 48 , no. 1 , pp. $68-80,2005$.
[42] J. Ju and J. Xu, "Surface stepped subsidence related to top-coal caving longwall mining of extremely thick coal seam under shallow cover," International Journal of Rock Mechanics and Mining Sciences, vol. 78, pp. 27-35, 2015. 